\title{
The H. pylori-related virulence factor CagA influences the expression of chemokines CXCL10, CCL17, CCL20, CCL22, and their receptors by peripheral blood mononuclear cells from peptic ulcer patients
}

\author{
Shila JALALPOUR ${ }^{1}$, Vahid MIRZAEE $^{2}$, Mohammad TAHERI ${ }^{3}$, Mahmood Sheikh FATHOLLAHI ${ }^{4}$, \\ Hossain KHORRAMDELAZADEH ${ }^{1,5}$ and Abdollah JAFARZADEH ${ }^{1,5-7}$
}

\begin{abstract}
Background - During the Helicobacter pylori (HP) infection, the infiltration of the leukocytes into stomach mucosa is directed by locally produced chemokines that play a decisive role in infection outcome. The CagA is the most potent virulence factor of HP, so that the infection with $\mathrm{Cag}^{+}$strains is associated with more severe complications than infection with $\mathrm{Cag} A^{-}$HP. Objective - The aim was to determine the expression of chemokines CXCL10, CCL17, CCL20 and CCL22, and their receptors by $\mathrm{Cag} A^{+} \mathrm{HP}$ - and Cag $A^{-} \mathrm{HP}$-derived crude extract (HP-CE)-stimulated peripheral blood mononuclear cells (PBMCs) from peptic ulcer (PU) patients. Methods - The serum and the PBMCs were collected from $20 \mathrm{HP}-\mathrm{infected}$ PU patients, 20 HP-infected asymptomatic subjects (HIA) and 20 non-infected healthy subjects (NHS). The PBMCs were cultured in absence of stimulator or with $10 \mu \mathrm{g} \mathrm{Cag} A^{+} \mathrm{HP}$ crude extract ( $\left.\mathrm{Cag} A^{+} \mathrm{CE}\right), 10 \mu \mathrm{g} \mathrm{Cag} A^{-} \mathrm{HP}$ crude extract $\left(\mathrm{Cag} A^{-} \mathrm{CE}\right)$. Chemokines and receptors were measured by ELISA and real time-PCR respectively. Results - In PU patients, the production of chemokines CXCL10, CCL17, CCL20 and CCL22, and the expression of chemokine receptors CXCR3, CCR4 and CCR6 by $\mathrm{CagA}^{+} \mathrm{CE}$-induced PBMCs were significantly higher than non-stimulated and $\mathrm{Cag} A^{-} \mathrm{CE}$ stimulated cultures. The CXCL10 production by $\mathrm{Cag} A^{+} \mathrm{CE}$ stimulated PBMCs from HIA subjects was significantly higher than the equal cultures from PU and NHS groups. The CCL17 and the CCL20 production by non-stimulated, $\mathrm{Cag} A^{+} \mathrm{CE}$ stimulated, and $\mathrm{Cag} A^{-} \mathrm{CE}$ stimulated PBMCs from PU subjects were significantly higher than the equal cultures from NHS and HIA groups. The CCL22 production by non-stimulated, $\mathrm{Cag} A^{+} \mathrm{CE}$ stimulated and $\mathrm{Cag} A^{-}$CE stimulated PBMCs from NHS group were significantly higher than the equal cultures from HIA and PU groups. The $\mathrm{Cag} \mathrm{A}^{+} \mathrm{CE}$ stimulated PBMCs from HIA subjects expressed lower amounts of CCR6 in comparison with $\mathrm{Cag} \mathrm{A}^{+} \mathrm{CE}$ stimulated PBMCs from NHS and PU groups. The serum levels CXCL10 and CCL20 in PU and HIA groups were significantly higher than NHS subjects. NHS and HIA groups displayed higher serum levels of CCL22 in comparison with PU patients. Conclusion - Results indicated that the Cag $A$ status of bacterium influence the expression of chemokines and receptors by HP-CE stimulated PBMCs from PU patients.
\end{abstract}

HEADINGS - Helicobacter pylori. CagA. Chemokines. Chemokine receptors. Peptic ulcer.

\section{INTRODUCTION}

The gastric Helicobacter pylori (HP) colonization usually occur during childhood, but the HP-related gastrointestinal disorders such as peptic ulcer (PU), gastric cancer and mucosa associated lymphoma may express in a proportion of the infected individuals after many years later ${ }^{(1)}$. Further, a potent association was indicated, especially between infection with cytotoxin-associated gene $\mathrm{A}(\mathrm{Cag} A)$-positive strains with a number of extra-intestinal disorders, such as cardiovascular, neurologic, hematologic, metabolic, and dermatologic diseases ${ }^{(2-4)}$. The interplay between host immune and genetic param- eters, virulence factors of HP and environmental elements influence the expression of the HP-related gastro-intestinal disorders ${ }^{(5,6)}$. HP-derived virulence factor $\operatorname{Cag} A$ is a potent immunogenic and oncogenic protein that is encoded by a gene placed at the end of pathogenic island. According to the existence or absence of $\operatorname{Cag} A$, the HP strains were classified into $\operatorname{Cag} A$-positive or $\operatorname{Cag} A$-negative strains $^{(7,8)}$. Almost $60.0 \%$ of HP strains isolated in Western countries were identified as $\operatorname{Cag} A$-positive, whilst almost all of the HP isolates from East Asian countries are $\operatorname{Cag} A$-positive. Clinically, infection with the $\operatorname{Cag} A$-positive strains of HP were associated with higher scores of gastric mucosal inflammation as well as severe atrophic

Declared conflict of interest of all authors: none

Disclosure of funding: This study was supported by a grant (NO: PN-96024) from Rafsanjan University of Medical Sciences, Rafsanjan, Iran.

${ }^{1}$ Molecular Medicine Research Center, Research Institute of Basic Medical Sciences, Rafsanjan University of Medical Sciences, Rafsanjan, Iran. ${ }^{2}$ Department of Internal Medicine, Rafsanjan University of Medical Sciences, Rafsanjan, Iran. ${ }^{3}$ Department of Microbiology, School of Medicine, Hamadan University of Medical Sciences, Hamadan, Iran. ${ }^{4}$ Rajaie Cardiovascular Medical and Research Center, Iran University of Medical Sciences, Tehran, Iran. ${ }^{5}$ Department of Immunology, School of Medicine, Rafsanjan University of Medical Sciences, Rafsanjan, Iran. ${ }^{6}$ Department of Immunology, School of Medicine, Kerman University of Medical Sciences, Kerman, Iran. ${ }^{7}$ Immunology of Infectious Diseases Research Center, Research Institute of Basic Medical Sciences, Rafsanjan University of Medical Sciences, Rafsanjan, Iran.

Corresponding author: Abdollah Jafarzadeh. E-mail: jafarzadeh14@yahoo.com 
gastritis and greater risk of development of gastric carcinoma ${ }^{(7)}$. HP-derived $\operatorname{Cag} A$ is translocated into host cells following attachment of the bacteria to the cell via the type IV secretion system ${ }^{(8)}$. Within the host cell, $\operatorname{Cag} A$ is phosphorylated by host cell kinases on tyrosine residue at certain motifs present at the $\mathrm{C}$-terminal region of the protein, leading to morphological changes in the cell. Moreover, $\operatorname{Cag} A$ can act directly in an unphosphorylated process to affect cellular tight junction, cellular expansion and differentiation, cellular polarity, cellular scattering, cellular elongation, and induction of the inflammatory reactions ${ }^{(9)}$. After injection into the cytoplasm of host cells, $\operatorname{Cag} A$ binds to various proteins, then interrupts the normal signal transduction of gastric epithelial cells involved in chronic inflammation and malignancy by changing the cell polarity, apoptosis, and proliferation ${ }^{(8,9)}$. Various cell types especially neutrophils, mast cells, dendritic cells, macrophages, and CD4 ${ }^{+}$- and $\mathrm{CD}^{+}$lymphocytes are accumulated into the gastric mucosa during HP infection. Chemokines induce leukocyte migration via binding to their receptors and contributes to the immunity and inflammation $^{(10-13)}$. It was reported that the proper and improper induction of Th1- and Th17 cell-mediated responses were associated with HP elimination or development of the pathological consequences (such as PU and gastritis), respectively ${ }^{(14)}$. Further, the balanced and great induction of Th2- and Treg cell-mediated responses were associated with an asymptomatic and development of the gastric malignancies, respectively ${ }^{(14,15)}$. The aim of this research were evaluate the expression of a Th1 cell-related chemokine and its receptor (CXCL10, and CXCR3), Th17 cell-related chemokine and its receptor (CCL20, and CCR6), and Th2- and Treg cell-related chemokines and their receptors (CCL17, CCL22, and CCR4) by $\mathrm{Cag} A^{+} \mathrm{CE}$ and $\mathrm{Cag} A^{-} \mathrm{CE}$ stimulated peripheral blood mononuclear cells (PBMCs) from noninfected healthy subjects (NHS), HP-infected asymptomatic subjects (HIA) and PU patients to compare any association ${ }^{(15)}$.

\section{METHODS}

\section{Subjects}

Totally, three groups including HP-infected PU patients $(n=20)$, HP-infected HIA subjects $(n=20)$ and NHS subjects $(n=20)$ were registered to study. The PU patients were enrolled among patients who were admitted to the Ali-ebne Abitale Hospital affiliated to the Rafsanjan University of Medical Sciences. The existence of PU was observed by endoscopic examination from digestive system. The PU patients did not receive medicine treatment (including nonsteroidal anti-inflammatory drugs) at the time of inclusion. In PU patients, the HP status was clarified by assessment of the specific plasma anti- HP antibodies using ELISA and by rapid urease test (RUT) that reformed on a biopsy sample that was collected from the gastric antrum area during endoscopic examination. The HP-infected PU patients were positive for both tests (HP-specific IgG and RUT).

The endoscopic examination was not performed for NHS and HIA groups and their HP status was estimated based on the determination of the specific plasma anti- HP antibodies. The HIA subjects exhibit a positive reaction of anti- HP IgG and the NHS were seronegative for both IgG and IgA against HP. The NHS and the HIA persons were selected among healthy blood donors and had no previous gastrointestinal disorders, without other chronic or acute disorders. A peripheral blood sample $(15 \mathrm{~mL})$ was obtained from each participant and was processed within 1 hour for separation of plasma and PBMCs. The separated plasma samples were stored at $-70^{\circ} \mathrm{C}$ freezer until analyses.

\section{Preparation of the $\mathrm{Cag} A^{+} \mathrm{CE}$ and $\mathrm{Cag} \mathrm{A}^{-} \mathrm{CE}$}

The $C a g A$-positive and $\operatorname{Cag} A$-negative strains of HP were obtained from Pasteur Institute of Iran (Tehran, Iran). The HP colonies were suspended in sterile distilled water at and disrupted using sonication on ice for 5 minutes. The HP-derived debris and unbroken bacteria were removed by centrifugation at $8000 \mathrm{~g}$ at $4^{\circ} \mathrm{C}$ for $10 \mathrm{~min}$. The supernatants were aliquoted and stored at $-70^{\circ} \mathrm{C}$ after measurement the protein concentrations their OD at $280 \mathrm{~nm}$ using a spectrophotometric system.

\section{Assessment of HP-specific antibodies}

The plasma amounts of the specific anti-HP antibodies were determined by commercial ELISA kits (Ideal Tashkhis; Iran) according to the kit guidelines.

\section{Separation and culturing of PBMCs}

The peripheral blood mononuclear cells (PBMCs) were separated from heparinized peripheral blood samples by densitygradient centrifugation on Ficoll (Biowest; France). Briefly, the blood sample was diluted with the same volume of PBS and then centrifuged on Ficoll at $2000 \mathrm{rpm}$ for 20 minutes. Then the layer of PBMCs was slowly removed from on the Ficoll, and washed with PBS (Shellmax; China). Finally, The PBMCs were suspended in DMEM High (Shellmax; China), supplemented with FBS (Shell$\max$; China), $(10 \% \mathrm{~V} / \mathrm{V}), 100 \mathrm{U} / \mathrm{mL}$ penicillin, and $0.1 \mathrm{mg} / \mathrm{mL}$ streptomycin (Shellmax; China). The viability of PBMCs was estimated using trypan blue staining and the cells with viability $>95 \%$ used for more analysis.

The PBMCs from PU, HIA and NHS were cultured (in 24-well plates) at $2 \times 10^{6}$ cells $/ \mathrm{mL} /$ well. The PBMCs from each participant were cultured (at $37^{\circ} \mathrm{C}$ in a humidified atmosphere with $5 \% \mathrm{CO}_{2}$ ) for 36 hours in absence of stimulator, or with $10 \mu \mathrm{g} \mathrm{Cag}^{+} \mathrm{HP}$-derived crude extract $\left(\mathrm{Cag} A^{+} \mathrm{CE}\right)$, and $10 \mu \mathrm{g} \mathrm{Cag} A^{-}$HP-drived crude extract ( $\left.\mathrm{Cag} A^{-} \mathrm{CE}\right)$. The concentrations of chemokines in culture supernatants and in serum samples were measured by ELISA. The expression of the chemokine receptors by PBMCs was determined using real time-PCR.

\section{Total RNA extraction from PBMCs and real time-PCR}

An RNA isolation kit (Pars-Tous, Iran) was used to extract the total RNA from cultured PBMCs. The quality of the extracted RNA was assessed by electrophoresis on the agarose gel. The purity of the separated RNA was measured on the basis of its absorption at $260 \mathrm{~nm}$ and $280 \mathrm{~nm}$ using a spectrophotometer system (NanoDrop DNovix, USA). The extracted RNA was converted to the complementary DNA (cDNA) using cDNA synthesis kit (Pars-Tous; Iran). The reverse transcription program was designed as: $65^{\circ} \mathrm{C}$ for 5 minutes (without reverse transcription enzyme), addition of reverse transcription enzyme, incubation at $20^{\circ} \mathrm{C}$ for 1 min (cooling stage), $47^{\circ} \mathrm{C}$ for 60 minutes, and finally the program was completed by a stage at $70^{\circ} \mathrm{C}$ for 10 minutes to terminate the activity of the reverse transcription enzyme. The assessment of the expression of CCR4, CCR6 and CXCR 3 genes was performed using a real-time PCR system (Applied Biosystems; USA) using a SYBR green master mix (Takara Clontech; Japan), mixed with $1 \mu \mathrm{L}$ of cDNA with proper primers (TABLE 1). The program of the thermal cycling was designed as: one initial stage (15 minutes) of $95^{\circ} \mathrm{C}, 40$ cycles of $60^{\circ} \mathrm{C}$ for 30 seconds, $72^{\circ} \mathrm{C}$ for 40 seconds, and eventually $95^{\circ} \mathrm{C}$ for 1 minutes. The $\beta$-actin gene was used as a housekeeping gene to normalize the amplified chemokine receptor 
TABLE 1. The CCR4, CCR6, CXCR3 and $\beta$-actin primers.

\begin{tabular}{ccc}
\hline Gene & Primer & $\begin{array}{c}\text { Product } \\
\text { size (bp) }\end{array}$ \\
\hline CCR4 & Forward: 5- TGTGGGCTCCAAATTTACT-3 & 57 \\
& Reverse:3-TGGTGGACTGCGTGTAAGATG-5 & \\
CCR6 & Forward: 5-CGGCTCCGATCCAGAACA-3 & \\
& Reverse: 3-CCCACACAACAAGGCAGATG-5 & 55 \\
& Forward: 5-TGGCCTGCATCAGCTTTG-3 & \\
CXCR3 & Reverse: 3-GGTAGAGCTGGGTGGCATGA-5 & \\
& $\begin{array}{l}\text { Forward: 5-GATCAGCAAGCAGGAGTATG-3 } \\
\text { 3-actin }\end{array}$ & \multirow{2}{*}{88} \\
& Reverse: 3-GTGTAACGCAACTAAGTCATAG-5 & \\
\hline
\end{tabular}

genes. The amount of the CCR4, CCR6 and CXCR3 expression calculated by the $2^{-\Delta \Delta \mathrm{Ct}}$ formula and displayed as units relative to the amount of $\beta$-actin expression.

\section{Detection of the CXCL10, CCL17, CCL20 and CCL22 levels in the PBMC supernatants and serum}

The levels of the investigated chemokines in the supernatants of cultured PBMCs and plasma samples were quantified using commercial ELISA kits [CXCL10, CCL17, CCL20: (BioLegend, US), and CCL22 (R \& D; US)].

\section{Statistical analysis}

The results were reported as mean \pm standard error of the mean (SEM). Differences in variables were analyzed by using proper statistical tests, including ANOVA, Student $t, \chi 2$, Mann-Whitney U test, Kruskal-Wallis test. The data were analyzed by a statistical SPSS software package (version 21, Chicago, IL, USA).

\section{RESULTS}

\section{Demographic characteristics of participants}

The means of ages were $41.40 \pm 7.021$ years in NHS group,

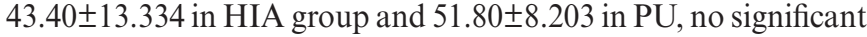
difference was observed between three groups concerning the ages $(P=0.109)$. The ratios of men/women were $12 / 8 \mathrm{n}(60 / 40 \%)$ NHS group, $12 / 8 \mathrm{n}(60 / 40 \%)$ in HIA and $12 / 8 \mathrm{n}(60 / 40 \%)$ PU, no significant difference was also found between HIA, NHS and PU concerning the gender distribution $(P=1)$.

\section{Chemokines production by non-stimulated and stimulated PBMCs from NHS, HIA and PU groups}

In PU patients, the production of CXCL10, CCL17, CCL20 and CCL22 by $\mathrm{Cag} A^{+} \mathrm{CE}$-induced PBMCs was significantly higher than non-stimulated and $\operatorname{Cag} A^{-} \mathrm{CE}$ stimulated cultures $(P=0.015$ and $P=0.001 ; P=0.001$ and $P=0.006 ; P=0.003$ and $P=0.001$; and $P=0.003$ and $P=0.001$, respectively) (FIGURE $1 . A-$ FIGURE 1.D).

In HIA subjects, the CXCL10 and CCL20 production by $\mathrm{Cag} \mathrm{A}^{+}$ $\mathrm{CE}$ induced PBMCs was significantly higher than non-stimulated and $\operatorname{Cag} A^{-}$CE stimulated cultures $(P=0.005$ and $P=0.001 ; P=0.001$ and $P=0.021$, respectively). In HIA subjects, the CCL17 production by $\mathrm{Cag} \mathrm{A}^{+} \mathrm{CE}$ induced PBMCs was higher than non-stimulated and $\operatorname{Cag} A^{-} \mathrm{CE}$ stimulated cultures, but difference was not significant. The CCL20 production by $\mathrm{Cag} A^{+} \mathrm{CE}$ induced PBMCs from HIA

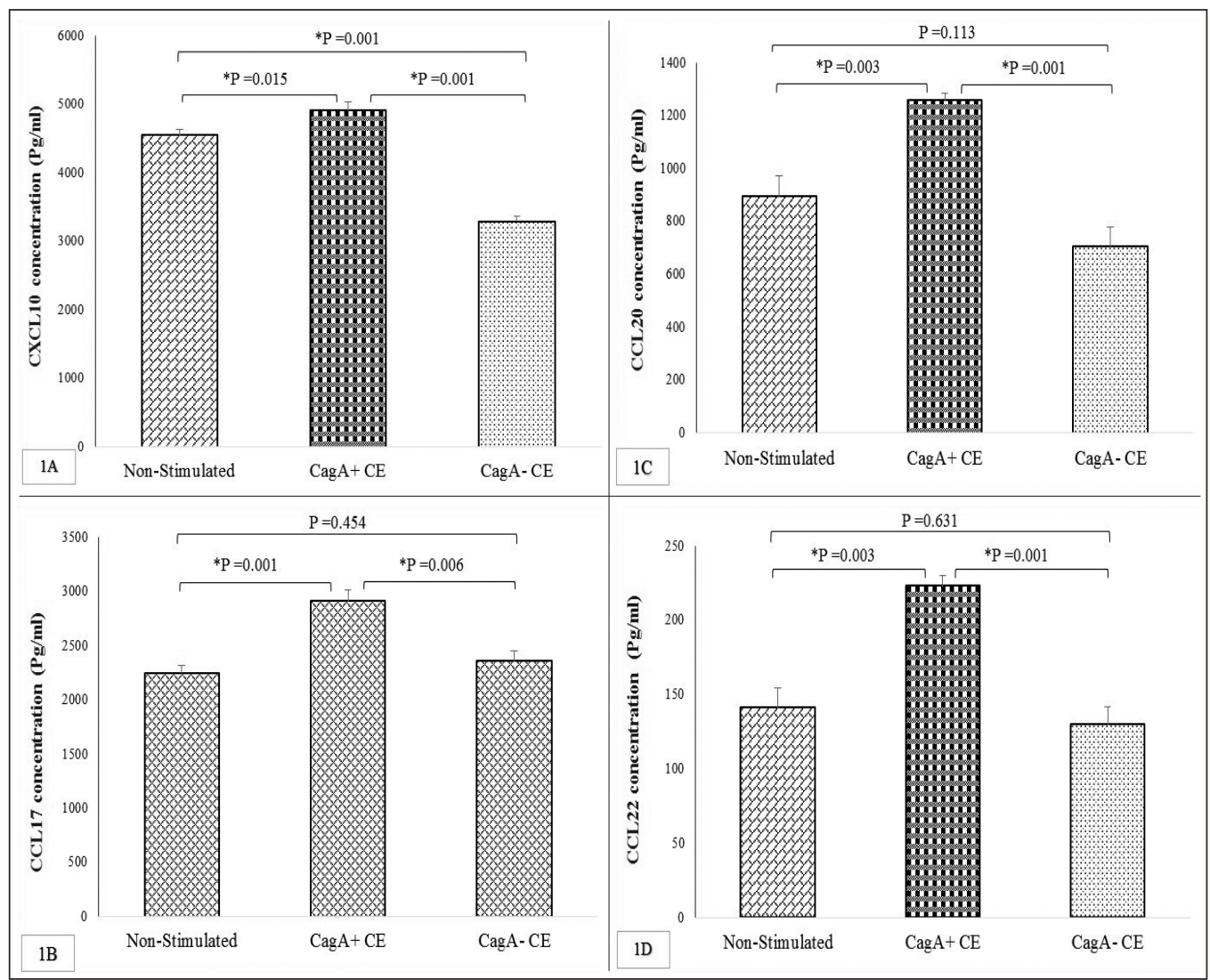

FIGURE 1. CXCL10, CCL17, CCL20 and CCL22 production by non-stimulated and stimulated PBMCs from PU patients. A. The CXCL10 production in $\mathrm{CagA}^{+} \mathrm{CE}$-induced PBMCs was significantly higher than non-stimulated and $\operatorname{Cag} A$ CE-stimulated cultures $(P=0.015$ and $P=0.001$, respectively). The CXCL10 production in $\mathrm{Cag} \mathrm{A}^{-}$ CE was significantly lower than non-stimulated cultures $(P=0.001)$.

B. The CCL17 production by CagA $A^{+}$CE-induced PBMCs was significantly higher than nonstimulated and $\mathrm{CagA}^{-}$ CE-stimulated cultures $(P=0.001$ and $P=0.006$, respectively). C. The CCL20 production by CagA ${ }^{+}$CE-induced PBMCs was significantly higher than non-stimulated and $C a g A$ CE-stimulated cultures $(P=0.003$ and $P=0.001$, respectively). D. The CCL22 production by $\mathrm{CagA}^{+} \mathrm{CE}$-induced PBMCs was significantly higher than non-stimulated and $\mathrm{CagA}$ CE-stimulated cultures $(P=0.003$ and $P=0.001$, respectively) 
subjects was significantly higher than non-stimulated cultures $(P=0.001)$. However, no significant difference was detected between non-stimulated and $\mathrm{Cag} A$ - CE stimulated cultures from HIA subjects concerning the CCL17, CCL20 and CCL22 production (FIGURE 2.A - FIGURE 2.D).

The CXCL10 and CCL20 production by $\mathrm{Cag}^{+} \mathrm{CE}$ induced PBMCs from NHS individuals was significantly higher than $\mathrm{Cag} A$ CE stimulated cultures $(P=0.001)$. The CXCL10 and CCL20 production in $\operatorname{Cag} A^{-} \mathrm{CE}$ was significantly lower than non-stimulated cultures ( $P=0.004$ and $P=0.013$, respectively). The differences of the CCL17 and CCL22 production by non-stimulated and $\mathrm{Cag} \mathrm{A}^{+} \mathrm{CE}$ stimulated PBMCs from NHS individuals were not significant (FIGURE 3.A - FIGURE 3.D).

\section{The expression of chemokines receptors by non-stimulated and stimulated PBMCs from NHS, HIA and PU groups}

In PU patients, the CXCR3, CCR 4 and CCR6 expression by $\mathrm{Cag}^{+} \mathrm{CE}$ induced PBMCs was higher than non-stimulated and $\operatorname{Cag} A^{-} \mathrm{CE}$ stimulated cultures $P=0.036, \mathrm{P}=0.001$ and $P=0.470$, $P=0.001$ and $P=0.002$ and $P<0.001$, respectively). (FIGURE 4.A - FIGURE 4.C). The CXCR3, CCR4 and CCR6 expression by $\operatorname{Cag} A^{-} \mathrm{CE}$ stimulated PBMCs from PU patients was significantly lower than non-stimulated cultures $(P=0.014, P=0.001$ and $P=0.001$, respectively) (FIGURE 4.A - FIGURE 4.C).

In HIA subjects, the CXCR3, CCR4 and CCR6 expression by $\mathrm{Cag}^{+} \mathrm{CE}$ induced PBMCs was significantly higher than non-stimulated and $\operatorname{Cag} A^{-} \mathrm{CE}$ stimulated cultures $(P=0.001$ and $P=0.001$;
$P=0.011$ and $P=0.001$; and $P=0.001$ and $P=0.001$, respectively) (FIGURE 5.A - FIGURE 5.C). The CXCR3, CCR4 and CCR6 expression by $\mathrm{Cag} A^{-} \mathrm{CE}$ stimulated PBMCs from PU patients was significantly lower than non-stimulated cultures $(P=0.001)$ (FIGURE 4.A - FIGURE 4.C).

The CXCR3, CCR4 and CCR6 expression by $\mathrm{Cag}^{+} \mathrm{CE}$ induced PBMCs from NHS group was significantly higher than Cag $A^{-}$CE stimulated cultures $(P=0.001, P=0.038$ and $P=0.001$, respectively). The CCR6 expression by $\mathrm{Cag} A^{+} \mathrm{CE}$ stimulated PBMCs was significantly higher than non-stimulated cultures $(P=0.004)$. The CXCR3, CCR4 and CCR6 expression in $\mathrm{Cag} A^{-}$- CE was significantly lower than non-stimulated cultures $(P=0.002, P=0.027$, and $P=0.002$, respectively). (FIGURE 6.A - FIGURE 6.C).

\section{Comparison of the chemokines production by non-stimulated and stimulated-PBMCs between NHS, HIA and PU groups}

The CXCL10 production by $\mathrm{Cag} A^{+}$CE stimulated PBMCs from HIA subjects was significantly higher than the equal cultures from PU and NHS groups $(P=0.016$ and $P=0.002$, respectively) (FIGURE 7.A). The CCL17 production by non-stimulated, $\mathrm{Cag} A^{+}$ $\mathrm{CE}$ stimulated and $\mathrm{Cag} A$ - CE stimulated PBMCs from PU subjects was significantly higher than the equal cultures from NHS and HIA groups $(P=0.001$ and $P=0.003 ; P=0.001$ and $\mathrm{P}=0.001$; and $P=0.001$ and $P=0.007$, respectively). The CCL17 production by $\mathrm{Cag} A^{+} \mathrm{CE}$ stimulated and $\operatorname{Cag} A^{-} \mathrm{CE}$ stimulated PBMCs from HIA subjects was higher than the equal cultures from NHS group, but differences were not significant (FIGURE 7.B).

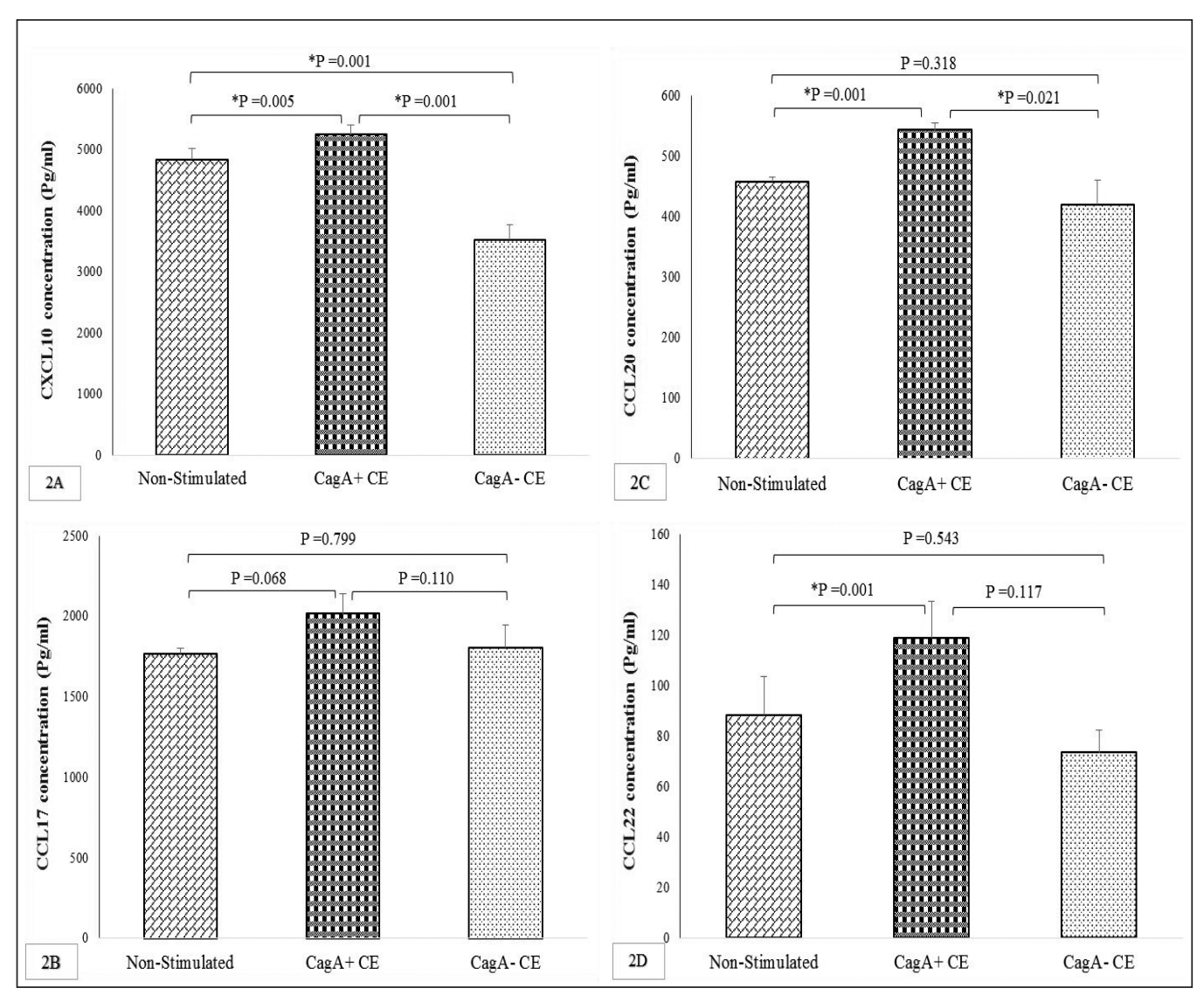

FIGURE 2. CXCL10, CCL17, CCL20 and CCL22 production by non-stimulated and stimulated PBMCs from HIA group. A. The CXCL10 production by $\mathrm{Cag} A^{+} \mathrm{CE}$-induced PBMCs was significantly higher than nonstimulated and $\operatorname{CagA}$ CE-stimulated cultures $(P=0.005$ and $P=0.001$, respectively). The CXCL10 production in $\mathrm{CagA}^{-}$ $\mathrm{CE}$ was significantly lower than non-stimulated cultures $(P=0.001)$. B. The CCL17 production by $\mathrm{CagA}^{+} \mathrm{CE}$-induced PBMCs was significantly higher than nonstimulated and $C a g A$

CE-stimulated cultures, but differences were not significant. C. The CCL20 production by $\mathrm{CagA} \mathrm{A}^{+} \mathrm{CE}$-induced PBMCs from HIA subjects was significantly higher than non-stimulated and $C a g A^{-} \mathrm{CE}$-stimulated cultures $(P=0.001$ and $P=0.021$, respectively).

D. The CCL22 production by CagA ${ }^{+} \mathrm{CE}$-induced PBMCs from HIA subjects was significantly higher than non-stimulated cultures $(P=0.001)$. The CCL17 production by $\mathrm{Cag} A^{+} \mathrm{CE}$-induced PBMCs was higher than CagA- CEstimulated cultures, but differences was not significant. 


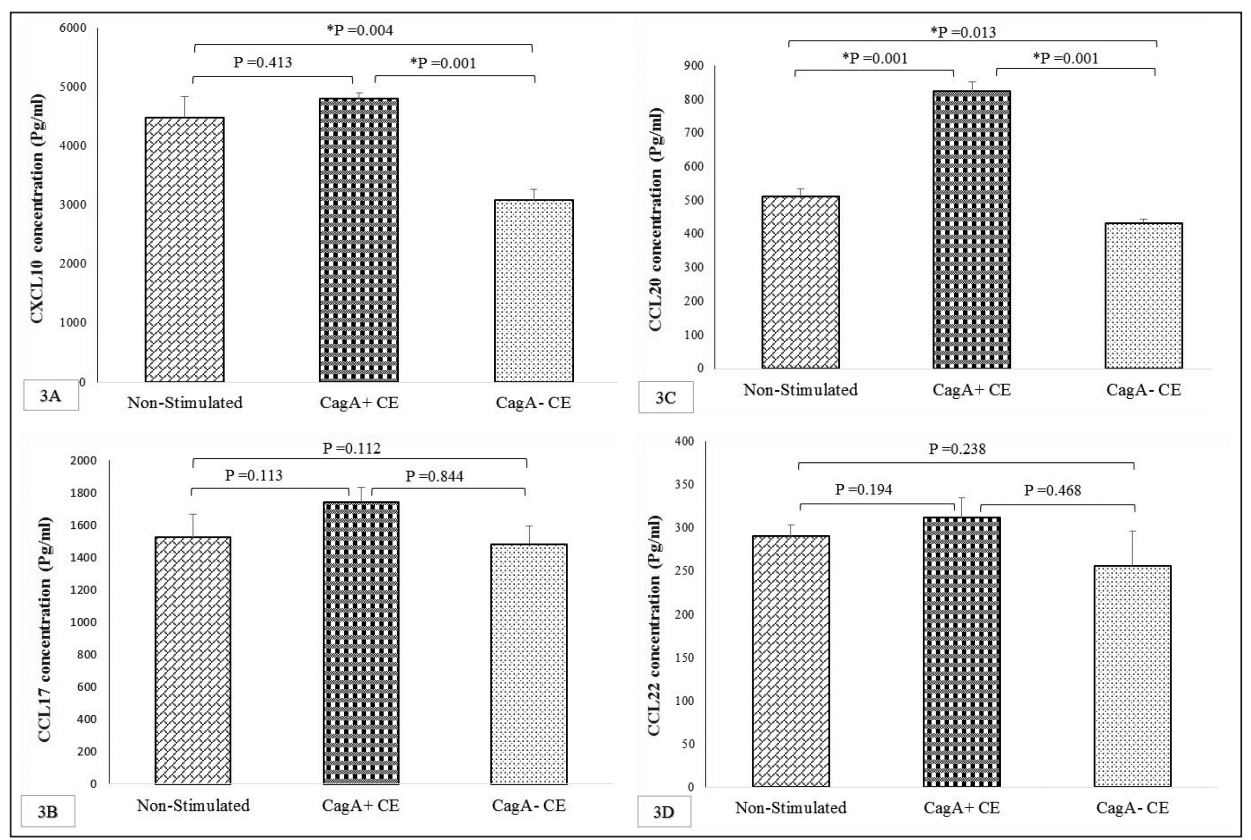

FIGURE 3. CXCL10, CCL17, CCL20 and CCL22 production by nonstimulated and stimulated PBMCs from NHS group. A. The CXCL10 production in $\mathrm{CagA}^{+} \mathrm{CE}$-induced PBMCs from NHS individuals was significantly higher than CagA $A^{-}$CE-stimulated cultures $(P=0.001)$. The CXCL10 production in CagA- CE was significantly lower than non-stimulated cultures $(P=0.004)$.

B. The differences of the CCL17 production by non-stimulated and HP-CEstimulated PBMCs were not significant C. The CCL20 production in $\mathrm{Cag} A^{+} \mathrm{CE}-$ induced PBMCs from NHS individuals was significantly higher than nonstimulated- and $\mathrm{CagA}^{-}$

CE-stimulated cultures $(P=0.001$ and $P=0.001$, respectively). The CCL20 production in $\mathrm{CagA}$

CE was significantly lower than non-stimulated cultures $(P=0.013)$. $D$. The differences of the CCL22 production by non-stimulated and HP-CEstimulated PBMCs from

NHS individuals were not significant.

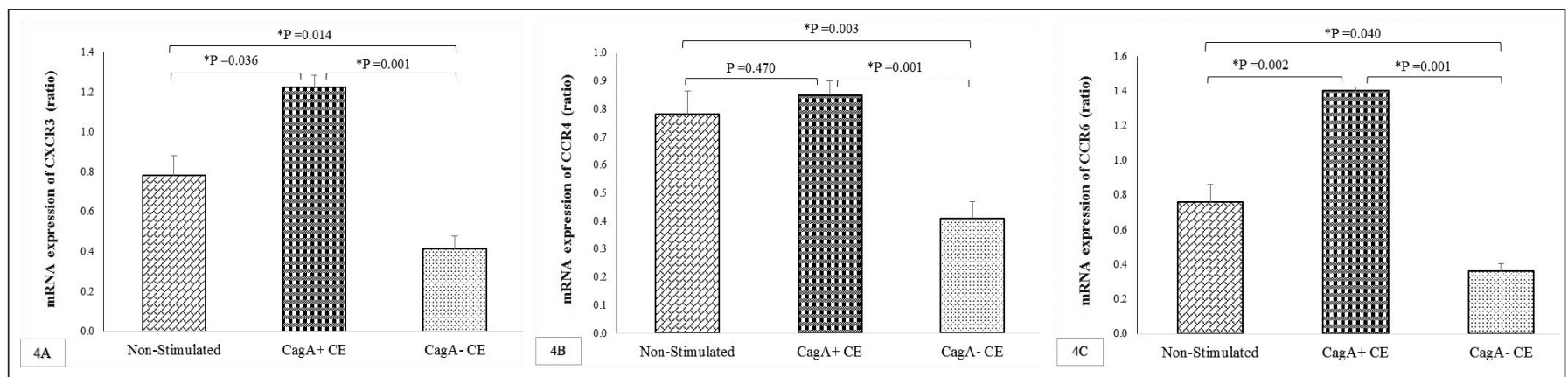

FIGURE 4. The CXCR3, CCR 4 and CCR6 expression by non-stimulated and stimulated PBMCs from PU patients. A. The CXCR3 expression by $C a g A^{+}$CE-induced PBMCs from PU patients was significantly higher than non-stimulated- and $C a g A^{-}$CE-stimulated cultures $(P=0.036$ and $P=0.001$, respectively). The CXCR3 expression by CagA- CE- stimulated PBMCs was significantly lower than non-stimulated cultures $(P=0.014)$. B. The CCR 4 expression by $\mathrm{Cag}^{+} \mathrm{CE}$-induced PBMCs from PU patients was significantly higher than $\mathrm{Cag} A^{-} \mathrm{CE}$-stimulated cultures $(P=0.001)$. The CCR 4 expression by $C$ ag $A^{-}$CE-stimulated PBMCs was significantly lower than non-stimulated cultures $(P=0.003)$. C. The CCR 6 expression by $C a g A^{+} \mathrm{CE}-i n d u c e d \mathrm{PBMCs}$ from PU patients was significantly higher than non-stimulated- and CagA- CE-stimulated cultures $(P=0.002$ and $P=0.001$, respectively). The CCR6 expression by $\mathrm{CagA}$ - CE- stimulated PBMCs was significantly lower than non-stimulated cultures $(P=0.040)$.

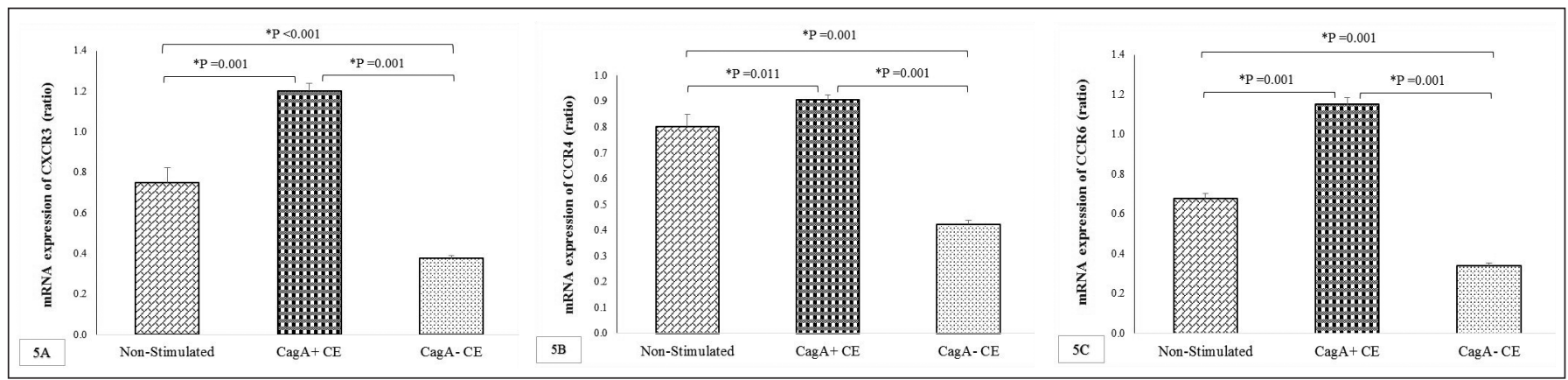

FIGURE 5. The CXCR3, CCR 4 and CCR6 expression by non-stimulated and stimulated PBMCs from HIA subjects. A. The CXCR3 expression by $C a g A^{+}$CE-induced PBMCs from HIA subjects was significantly higher than non-stimulated- and $C a g A^{-}$CE-stimulated cultures $(P=0.001$ and $P=0.001$, respectively). The CXCR3 expression by $C a g A^{-}$CE-stimulated PBMCs was significantly lower than non-stimulated cultures $(P<0.001)$. B. The CCR 4 expression by $\mathrm{Cag} A^{+} \mathrm{CE}$-induced PBMCs from HIA subjects was significantly higher than non-stimulated-and $\mathrm{Cag} A^{-} \mathrm{CE}$-stimulated cultures $(P=0.011$ and $P=0.001$, respectively). The CCR 4 expression by CagA- CE-stimulated PBMCs was significantly lower than non-stimulated cultures $(P=0.001)$. C. The CCR6 expression by $\mathrm{Cag} A^{+} \mathrm{CE}$-induced PBMCs from HIA subjects was significantly higher than non-stimulated-and $C a g A^{-} \mathrm{CE}-\mathrm{stimulated}$ cultures ( $P=0.001$ and $P=0.001$, respectively). The CCR6 expression by Cag $A^{-} \mathrm{CE}$-stimulated PBMCs was significantly lower than non-stimulated cultures $(P=0.001)$. 


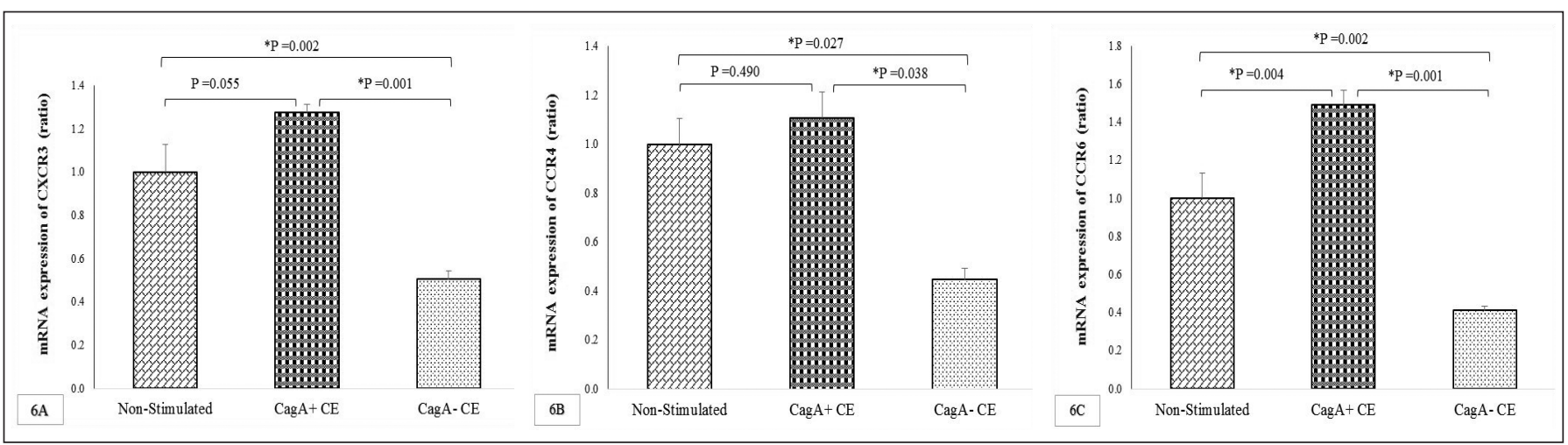

FIGURE 6. The CXCR3, CCR4 and CCR6 expression by non-stimulated and stimulated PBMCs from NHS group. A. The CXCR3 expression by $C a g A^{+}$CE-induced PBMCs from NHS group was significantly higher $C a g A^{-}$CE-stimulated cultures $(P=0.001)$. The CXCR3 expression by $C a g A^{-}$ $\mathrm{CE}$-stimulated PBMCs was significantly lower than non-stimulated cultures $(P=0.002)$. B. The CCR 4 expression by $C a g A^{+} \mathrm{CE}-i n d u c e d \mathrm{PBMCs}$ from NHS subjects was significantly higher than $\mathrm{CagA}^{-} \mathrm{CE}$-stimulated cultures $(P=0.038)$. The CCR 4 expression by $C a g A^{-} \mathrm{CE}-$ stimulated PBMCs was significantly lower than non-stimulated cultures $(P=0.027)$. C. The CCR6 expression by $\mathrm{Cag} A^{+} \mathrm{CE}$-induced PBMCs from NHS group was significantly higher than non-stimulated PBMCs and CagA- CE-stimulated cultures $\left(P=0.002\right.$ and $P=0.001$, respectively). . The CCR6 expression by $C a g A^{-}$CEstimulated PBMCs was significantly lower than non-stimulated cultures $(P=0.002)$.

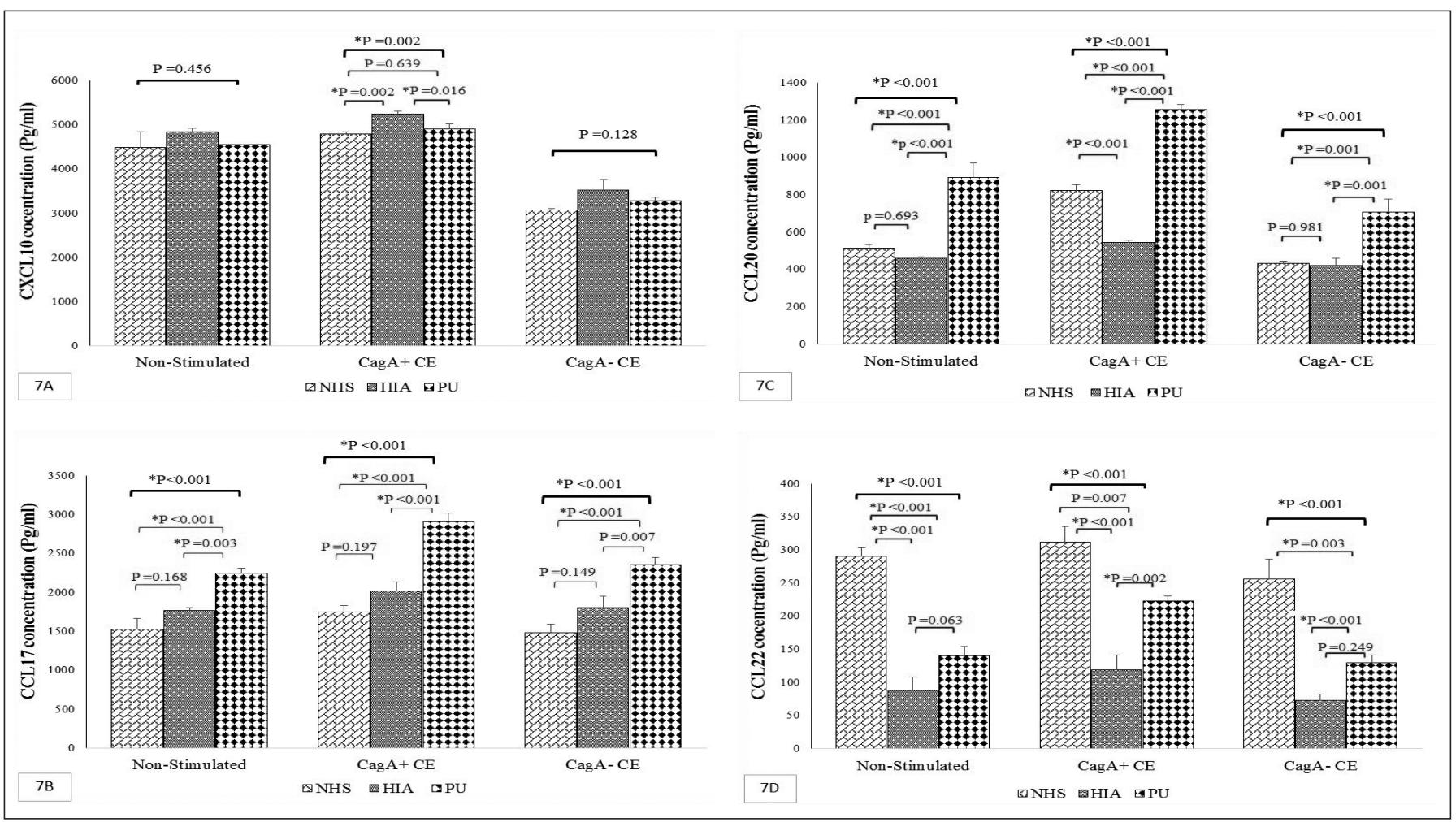

FIGURE 7. Comparison of the CXCL10, CCL17, CCL20 and CCL22 production by non-stimulated and stimulated-PBMCs from NHS, HIA and PU groups. A. The CXCL10 production by $\mathrm{Cag} A^{+} \mathrm{CE}$-stimulated PBMCs from HIA subjects was significantly higher than the equal cultures from PU and NHS groups $\left(P=0.016\right.$ and $P=0.002$, respectively). B. The CCL17 production by non-stimulated- $\mathrm{Cag} A^{+} \mathrm{CE}$ stimulated- and $\mathrm{Cag} A^{-} \mathrm{CE}-$ stimulated PBMCs from PU subjects was significantly higher than the equal cultures from NHS and HIA groups $(P<0.001$ and $P=0.003 ; P<0.001$ and $P<0.001$; and $P<0.001$ and $P=0.007$, respectively). The CCL17 production by Cag $A^{+}$CE stimulated- and CagA-CE-stimulated PBMCs from HIA subjects was higher than the equal cultures from NHS group, but differences were not significant. C. The CCL20 production by non-stimulated-, $\mathrm{Cag} A^{+} \mathrm{CE}$ stimulated- and CagA- CE-stimulated PBMCs from PU subjects was significantly higher than the equal cultures from NHS and HIA groups (all comparisons with $P \leq 0.001$ ). The CCL20 production similarly expressed by non-stimulated-, and CagA-CE stimulated-PBMCs between NHS and HIA groups. The CCL20 production by $\mathrm{Cag} A^{+} \mathrm{CE}$ stimulated PBMCs from NHS group was significantly higher than equal culture from HIA group $(P<0.001)$. D. The CCL22 production by non-stimulated-, $C a g A^{+}$CE stimulated- and CagA ${ }^{-}$CE-stimulated PBMCs from NHS group was significantly higher than the equal cultures from HIA and PU groups $(P<0.001$ and $P<0.001 ; P<0.001$ and $P=0.007 ;$ and $P<0.001$ and $P=0.003$, respectively). The CCL22 production by $\mathrm{Cag} A^{+} \mathrm{CE}$ stimulated- PBMCs from PU group was significantly higher than the equal culture from HIA group $(P<0.002)$. 
The CCL20 production by non-stimulated, $\operatorname{Cag} A^{+}$CE stimulated and $\mathrm{Cag} A^{-} \mathrm{CE}$ stimulated PBMCs from PU subjects was significantly higher than the equal cultures from NHS and HIA groups (all comparisons with $P=0.001$ ). The CCL20 production similarly expressed by non-stimulated, and $\mathrm{Cag} A^{-} \mathrm{CE}$ stimulated PBMCs between NHS and HIA groups. The CCL20 production by $\mathrm{Cag}^{+}$ CE stimulated PBMCs from NHS group was significantly higher than equal culture from HIA group $(P<0.001)$ (FIGURE 7.C).

The CCL22 production by non-stimulated, $\operatorname{Cag} A^{+} \mathrm{CE}$ stimulated and $\mathrm{Cag} A^{-} \mathrm{CE}$ stimulated PBMCs from NHS group was significantly higher than the equal cultures from HIA and PU groups $(P=0.001$ and $P=0.001 ; P=0.001$ and $P=0.007$; and $P=0.001$ and $P=0.003$, respectively (FIGURE 7.D).

\section{Comparison of the expression of the chemokine receptors by non-stimulated and stimulated-PBMCs between NHS, HIA and PU groups}

The differences of the CXCR 3 and CCR 4 expression by non-stimulated, $\mathrm{Cag} A^{+} \mathrm{CE}$ stimulated and $\mathrm{Cag} A^{-} \mathrm{CE}$ stimulated PBMCs between NHS, HIA and PU groups were not significant (FIGURE 8.A and FIGURE 8.B). The CCR6 expression by $\mathrm{Cag} \mathrm{A}^{+}$ CE stimulated PBMCs from HIA subjects was significantly lower than the equal cultures from NHS and PU groups $(P=0.001$ and $P=0.004$, respectively). The differences of the CCR6 expression by non-stimulated, and $\mathrm{Cag} A$. CE stimulated PBMCs between NHS, HIA and PU groups were not significant (FIGURE 8.C).

\section{Comparison of the chemokines production from serum between NHS, HIA and PU groups}

The serum levels of CXCL10 in PU and HIA groups were significantly higher than NHS subjects $(P<0.001$ and $P=0.018$ respectively). The difference of the serum levels of CXCL10 between PU and HIA groups was not significant (FIGURE 9.A). The differences of the serum levels of CCL17 between PU, HIA and NHS were not significant (FIGURE 9.B). The serum levels of CCL20 in PU and HIA groups were significantly higher than NHS subjects $(P<0.001)$. The difference of the serum levels of CCL20 between PU and HIA groups was not significant (FIGURE 9.C). However, the serum levels of CCL22 in NHS and HIA groups were significantly higher than PU patients $(P<0.001$ and $P=0.004$, respectively). The difference of the serum levels of CCL22 between NHS and HIA groups was not significant (FIGURE 9.D).

\section{DISCUSSION}

The results of the present study showed that in PU patients, the production of chemokines CXCL10, CCL17, CCL20 and CCL22, and the expression of chemokine receptors CXCR3, CCR4 and CCR6 by $\operatorname{Cag} A^{+} \mathrm{CE}$ induced PBMCs were significantly higher than non-stimulated and $\mathrm{Cag}^{-} \mathrm{CE}$ stimulated cultures. $\mathrm{Cag} A$ is considered as a powerful HP-related virulence factor contributes in the pathogenesis of HP-related disorders. Indeed, the infection with $C a g A$-positive HP strains were related with more severe gastric inflammation in comparison with $\mathrm{Cag} A$-negative strains and greater risk of PU and gastric cancer ${ }^{(14,16)}$. The $C a g A$-positive HP strains induce more CXCL8 as compared to $C a g A$-negative strain $^{(15)}$. Further, the higher CXCL8 expression was detected in gastric epithelial cells from patients with PU who infected with $\operatorname{Cag} A$-positive HP strains ${ }^{(17,18)}$. The mucosal quantities of IL- $1 \beta$ and IL-8 were markedly higher in samples infected with CagA-positive HP strains than those infected with $\operatorname{Cag} A$-negative strains ${ }^{(19)}$. The circulation TNF- $\alpha$ levels in $C a g A$-positive HP-infected patients were higher than control patients ${ }^{(20)}$. Further, a positive association was also indicated between infection with $\mathrm{Cag} A$-positive strains of HP and serum quantities of CXCL10 in patients with PU ${ }^{(21)}$. A positive association was also indicated between serum levels of IL-12, but not of IL-13 and infection with $\mathrm{Cag} A$-positive strains of $\mathrm{HP}^{(22)}$. It has been also indicated that the serum IL-17 quantities in PU patients infected with $\operatorname{Cag} A$-positive HP strains were higher than those infected with $\operatorname{Cag} A$-negative strains ${ }^{(23)}$.

CXCL10 also named interferon- $\gamma$-inducible protein 10 (IP10 ) is identified as a Th1 cell-attracting chemokines that is bound to CXCR3 which is mainly expressed on Th1 cells ${ }^{(24,25)}$. CCL20 also named liver-and activation-regulated chemokine (LARC) is identified as a Th17 cell-attracting chemokines that is bound to CCR6 which is mainly expressed on Th17 cells ${ }^{(24,25)}$. The capacity of $\mathrm{Cag} A$-positive HP strains to induce higher amounts of CXCL10 and CCL20 indicate that these strains induces higher accumulation

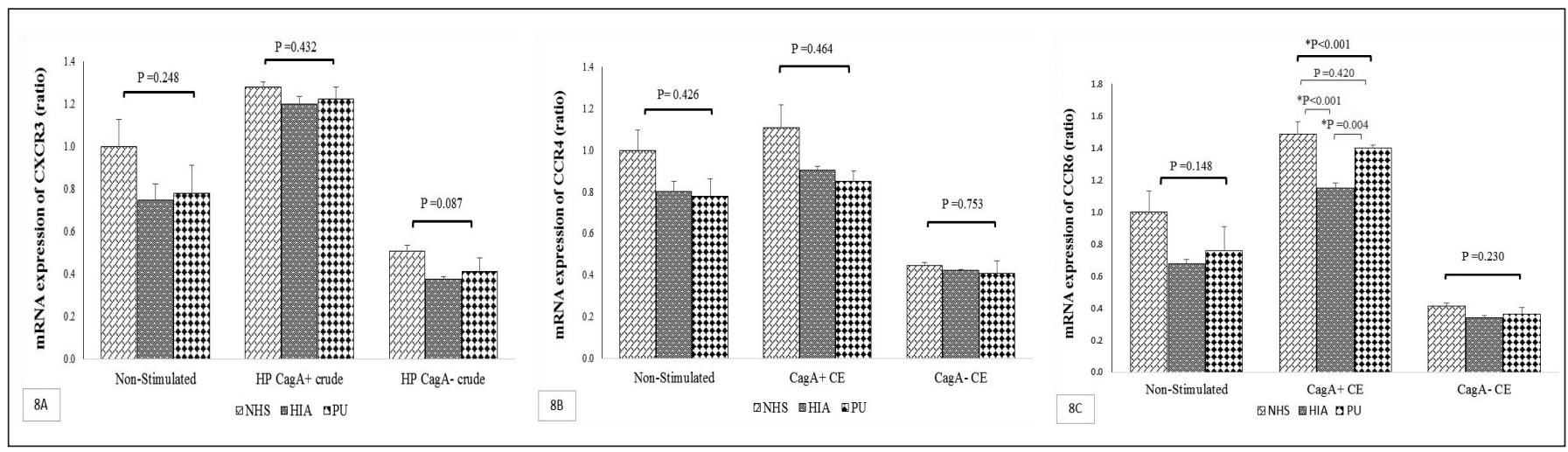

FIGURE 8. Comparison of the CXCR3, CCR4 and CCR6 expression by non-stimulated and stimulated-PBMCs from NHS, HIA and PU groups. A. The differences of the CXCR 3 expression by non-stimulated, CagA ${ }^{+}$CE stimulated- and CagA- CE-stimulated PBMCs between NHS, HIA and PU groups were not significant. B. The differences of the CCR 4 expression by non-stimulated, $C a g A^{+} \mathrm{CE}$ stimulated- and CagA- $\mathrm{CE}-\mathrm{stimulated}$ PBMCs between NHS, HIA and PU groups were not significant. C. The CCR6 expression by Cag $A^{+}$CE stimulated-PBMCs from HIA subjects was significantly lower than the equal cultures from NHS and PU groups $(P<0.001$ and $P=0.004$, respectively). The differences of the CCR6 expression by non-stimulated, and CagA-CE-stimulated PBMCs between NHS, HIA and PU groups were not significant. 


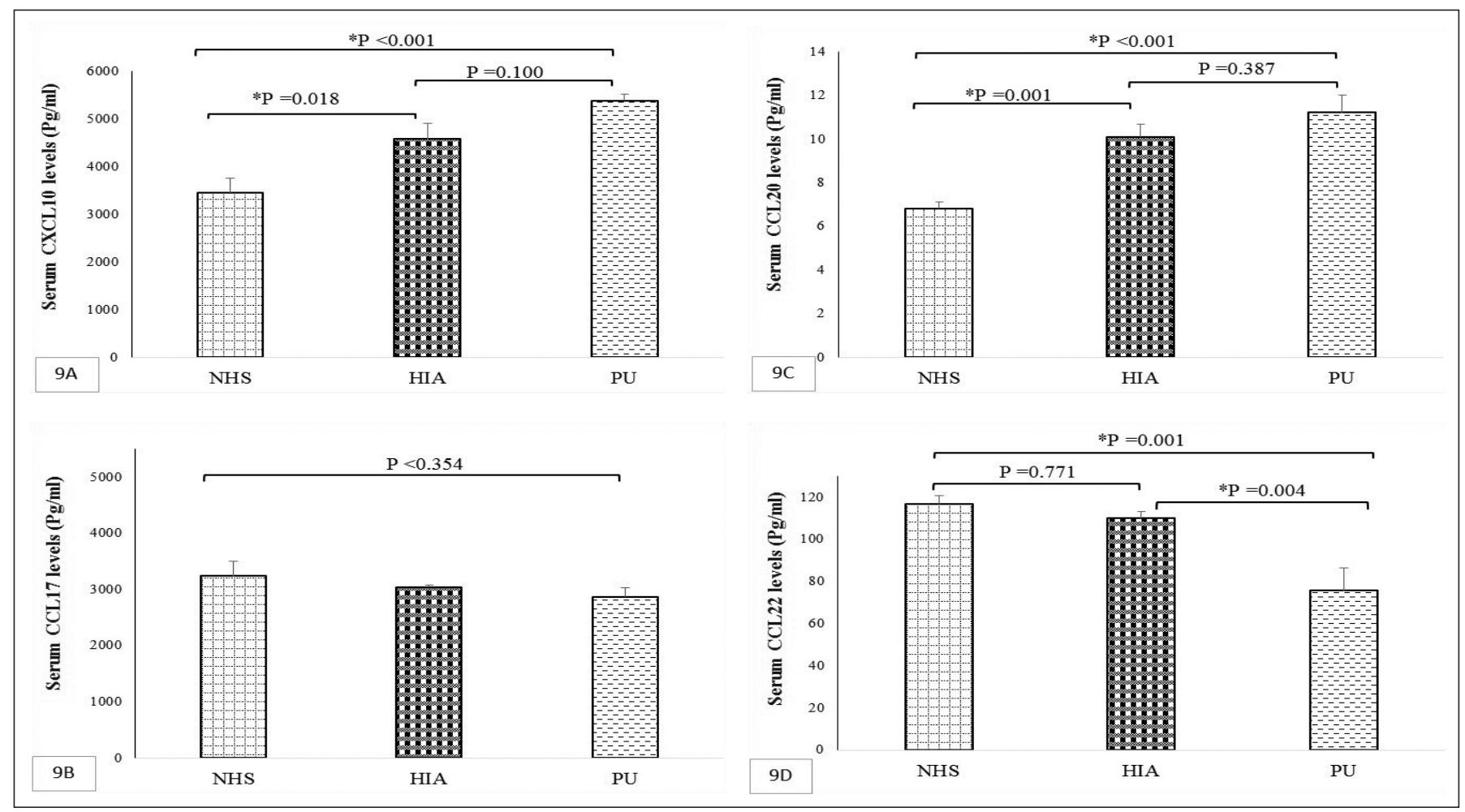

FIGURE 9. Serum CXCL10, CCL17, CCL20 and CCL22 levels in NHC, HIA and PU groups. A. The serum levels of CXCL10 in PU and HIA groups were significantly higher than NHS subjects $(P<0.001$ and $P=0.018$ respectively). The difference of the serum levels of CXCL10 between PU and HIA groups was not significant. B. The differences of the serum levels of CCL17 between PU, HIA and NHS were not significant. C. The serum levels of CCL20 in PU and HIA groups were significantly higher than NHS subjects $(P<0.001$ and $P=0.001$, respectively). The difference of the serum levels of CCL20 between PU and HIA groups was not significant. D. The serum levels of CCL22 in NHS and HIA groups were significantly higher than PU patients subjects $(P=0.001$ and $P=0.004$, respectively). The difference of the serum levels of CCL22 between NHS and HIA groups was not significant.

of Th1- and Th17 cells into the gastric mucosa that may promote the pathological consequences such as gastritis and PU. The ability of CagA-positive HP strains to induce higher CCL17 and CCL22 amounts also indicate that these strains induces higher accumulation of Th2- and Treg cells into the gastric mucosa that may promote the development of the malignancies due to promotion of the Th2- and Treg cell-mediated immunosuppression.

\section{CONCLUSION}

These results indicated that the $\operatorname{Cag} A$ status of HP influence the expression of chemokines CXCL10, CCL17, CCL20 and CCL22, and their receptors (CXCR3, CCR4 and CCR6) by HPCE stimulated PBMCs from PU patients. The modulation of the expression chemokines and their receptors in the correct direction may lead to the induction of a proper immune response against HP that can cause bacterium elimination and limit the consequences.

\section{ACKNOWLEDGEMENT}

Rafsanjan University of Medical Sciences grant number 96024 and Ethical Committee of Rafsanjan University of Medical Science code number IR.RUMS.REC.1395.157. The authors of the article thank the Rafsanjan University of Medical Sciences for the support of this research project.

\section{Authors' contribution}

Concept: Jafarzadeh A. Design: Jafarzadeh A. Supervision: Jafarzadeh A. Materials: Jalalpour S. Data collection and/or processing: Jalalpour S, Taheri M. Analysis and/or interpretation: Jalalpour S, Fathollahi MS. Literature search: Jalalpour S, Jafarzadeh A. Writing: Jalalpour S, Jafarzadeh A, Fathollahi MS. Critical review: Jalalpour S, Jafarzadeh A, Fathollahi MS, Mirzaee V, Khorramdelazadeh $\mathrm{H}$, Taheri M.

\section{Orcid}

Shila Jalalpour: 0000-0001-6244-6997.

Vahid Mirzaee: 0000-0003-0179-9224.

Mohammad Taheri: 0000-0003-4128-8613.

Mahmood Sheikh Fathollahi: 0000-0001-6144-3049.

Hossain Khorramdelazadeh: 0000-0002-0653-2724.

Abdollah Jafarzadeh: 0000-0002-8180-0602. 
Jalalpour S, Mirzaee V, Taheri M, Fathollahi MS, Khorramdelazadeh H, Jafarzadeh A. O fator de virulência relacionado ao $H$. pylori influencia a expressão de quimiocinas CXCL10, CCL17, CCL20, CCL22, e seus receptores por células mononucleares de sangue periféricos de pacientes com úlceras pépticas. Arq Gastroenterol. 2020;57(4):366-74.

RESUMO - Contexto - Durante a infecção por Helicobacter pylori (HP), a infiltração dos leucócitos na mucosa estomacal é dirigida por quimiocinas produzidas localmente que desempenham um papel decisivo no resultado da infecção. O Cag $A$ é o fator de virulência mais potente do HP, de modo que a infecção com cepas $\mathrm{Cag} A^{+}$está associada a complicações mais graves do que a infecção com $\operatorname{Cag} A^{-}$HP. Objetivo - O objetivo foi determinar a expressão das quimiocinas CXCL10, CCL17, CCL20 e CCL22, e seus receptores por Cag $A^{+}$HP- e Cag $A^{-}$extrato bruto (EB) derivado de HP (HP-EB) de células mononucleares do sangue periférico (CMSP) de pacientes com úlcera péptica (UP). Métodos - O soro e as CMSP foram coletados de 20 pacientes com UP infectados pelo HP, 20 indivíduos assintomáticos infectados pelo HP (AI-HP) e 20 indivíduos saudáveis não infectados pelo HP (NI-HP). As CMSP foram cultivadas na ausência de estimulador ou com extrato bruto $\mathrm{Cag} A^{+} \mathrm{HP} \operatorname{de} 10 \mu \mathrm{g}\left(\mathrm{Cag} A^{+} \mathrm{EB}\right), 10 \mu \mathrm{g} C a g A^{-}$extrato bruto HP ( $\left.\mathrm{Cag} A^{-} \mathrm{EB}\right)$. Quimiocinas e receptores foram medidos por ELISA e PCR em tempo real, respectivamente. Resultados - Em pacientes com UP a produção de quimiocinas CXCL10, CCL17, CCL20 e CCL22, e a expressão dos receptores de quimiocina CXCR3, CCR4 e CCR6 por Cag $A^{+}$ CMSP induzidos pelo EB foram significativamente maiores do que as culturas não estimuladas e CagA- EB estimulados. A produção de CXCL10 por $\mathrm{Cag} A^{+} \mathrm{EB}$ estimulou as CMSP de sujeitos AI-HP em proporção significativamente maior do que as culturas iguais dos grupos UP e NI-HP. A produção de CCL17 e CCL20 por grupos não estimulados, $C a g A^{+}$EB estimulado, e Cag $A^{-}$EB estimulou CMSP de sujeitos com UP e foram significativamente superiores às culturas iguais dos grupos NI-HP e AI-HP. A produção de CCL22 por grupos não estimulados, Cag $A^{+}$EB estimulado e $\mathrm{Cag} A^{-}$EB estimulado pelo grupo NI-HP foram significativamente maiores do que as culturas iguais dos grupos AI-HP e PU. O Cag $A^{+}$EB estimulou as CMSP dos sujeitos do AI-HP, expressando menores quantidades de CCR6 em comparação com as CMSP estimuladas pelo Cag $A^{+}$EB de grupos NI-HP e UP. Os níveis sanguíneos de CXCL10 e CCL20 nos grupos UP e AI-HP foram significativamente superiores aos dos sujeitos do NI-HP. Os grupos NI-HP e AI-HP apresentaram níveis sanguíneos mais elevados de CCL22 em comparação com pacientes com UP. Conclusão - Os resultados indicaram que o estado $\operatorname{Cag} A$ da bactéria influencia a expressão de quimiocinas e receptores por HP-EB estimulados CMSP de pacientes com UP.

DESCRITORES - Helicobacter pylori. Quimiocinas. Receptores de quimiocinas. Úlcera péptica.

\section{REFERENCES}

1. Walduck AK, Raghavan S. Immunity and Vaccine Development Against Helicobacter pylori. Adv Exp Med Biol. 2019;1149:257-75.

2. Jafarzadeh A, Rezayati MT, Nemati M. Helicobacter pylori seropositivity in patients with type 2 diabetes mellitus in South-East of Iran. Acta Med Iran. 2013;51:892-6.

3. Jafarzadeh A, Akbarpoor V, Nabizadeh M, Nemati M, Rezayati MT. Total leukocyte counts and neutrophil-lymphocyte count ratios among Helicobacter pylori-infected patients with peptic ulcers: independent of bacterial CagA status. Southeast Asian J Trop Med Public Health. 2013;44:82-8

4. Jafarzadeh A, Esmaeeli-Nadimi A, Nemati M, Tahmasbi M, Ahmadi P. Serum concentrations of Helicobacter pylori IgG and the virulence factor CagA in patients with ischaemic heart disease. East Mediterr Health J. 2010;16:1039-44.

5. Nemati M, Larussa T, Khorramdelazad H, Mahmoodi M, Jafarzadeh A. Tolllike receptor 2: An important immunomodulatory molecule during Helicobacter pylori infection. Life Sci. 2017;178:17-29.

6. Waskito LA, Salama NR, Yamaoka Y. Pathogenesis of Helicobacter pylori infection. Helicobacter. 2018;23(Suppl 1):e12516.

7. Nejati S, Karkhah A, Darvish H, Validi M, Ebrahimpour S, Nouri HR. Influence of Helicobacter pylori virulence factors CagA and VacA on pathogenesis of gastrointestinal disorders. Microb Pathog. 2018;117:43-8.

8. Tegtmeyer N, Neddermann M, Asche CI, Backert S. Subversion of host kinases: a key network in cellular signaling hijacked by Helicobacter pylori CagA. Mol Microbiol. 2017;105:358-72.

9. Teh M, Tan KB, Seet BL, Yeoh KG. Study of p53 immunostaining in the gastric epithelium of cagA-positive and cagA-negative Helicobacter pylori gastritis. Cancer. 2002;95:499-505.

10. David BA, Kubes P. Exploring the complex role of chemokines and chemoattractants in vivo on leukocyte dynamics. Immunol Rev. 2019;289:9-30.

11. Ruytinx P, Proost P, Van Damme J, Struyf S. Chemokine-Induced Macrophage Polarization in Inflammatory Conditions. Front Immunol. 2018;9:1930.

12. Hughes CE, Nibbs RJB. A guide to chemokines and their receptors. FEBS J. 2018;285:2944-71

13. Farnsworth RH, Karnezis T, Maciburko SJ, Mueller SN, Stacker SA. The Interplay Between Lymphatic Vessels and Chemokines. Front Immunol. 2019;10:518.
14. Jafarzadeh A, Larussa T, Nemati M, Jalapour S. T cell subsets play an important role in the determination of the clinical outcome of Helicobacter pylori infection. Microb Pathog. 2018;116:227-36.

15. Jafarzadeh A, Nemati M, Jafarzadeh $\mathrm{S}$. The important role played by chemokines influence the clinical outcome of Helicobacter pylori infection. Life Sci. 2019;231:116688.

16. Jafarzadeh A, Salari M. Seroprevalence of anti-Helicobacter pylori and anti-CagA antibodies in peptic ulcer and healthy subjects in the city of Rafsanjan. J Res Med Sci. 2006;11:285-91.

17. Gobert AP, Wilson KT. Human and Helicobacter pylori Interactions Determine the Outcome of Gastric Diseases. Curr Top Microbiol Immunol. 2017; 400:27-52.

18. Fazeli Z, Alebouyeh M, Rezaei Tavirani M, Azimirad M, Yadegar A. Helicobacter pylori CagA induced interleukin- 8 secretion in gastric epithelial cells Gastroenterol Hepatol Bed Bench. 2016;9(Suppl 1):S42-s6.

19. Yamaoka Y, Kita M, Kodama T, Sawai N, Kashima K, Imanishi J. Induction of various cytokines and development of severe mucosal inflammation by cagA gene positive Helicobacter pylori strains. Gut. 1997;41:442-51.

20. Collodel G, Moretti E, Campagna MS, Capitani S, Lenzi C, Figura N. Infection by CagA-positive Helicobacter pylori strains may contribute to alter the sperm quality of men with fertility disorders and increase the systemic levels of TNF-alpha. Dig Dis Sci. 2010;55:94-100.

21. Jafarzadeh A, Nemati M, Rezayati MT, Khoramdel H, Nabizadeh M, Hassanshahi G, et al. Lower circulating levels of chemokine CXCL10 in Helicobacter pylori-infected patients with peptic ulcer: Influence of the bacterial virulence factor CagA. Iranian J Microbiol. 2013;5:28-35.

22. Eskandari-Nasab E, Sepanjnia A, Moghadampour M, Hadadi-Fishani M, Rezaeifar A, Asadi-Saghandi A, et al. Circulating levels of interleukin (IL)12 and IL-13 in Helicobacter pylori-infected patients, and their associations with bacterial CagA and VacA virulence factors. Scand J Infect Dis. 2013; 45:342-9.

23. Jafarzadeh A, Mirzaee V, Ahmad-Beygi H, Nemati M, Rezayati MT. Association of the CagA status of Helicobacter pylori and serum levels of interleukin (IL)-17 and IL-23 in duodenal ulcer patients. J Dig Dis. 2009;10:107-12.

24. Davids MS, Burger JA. Cell Trafficking in Chronic Lymphocytic Leukemia. Open J Hematol. 2012;3(S1):3.

25. Du H, Gao L, Luan J, Zhang H, Xiao T. C-X-C Chemokine Receptor 4 in Diffuse Large B Cell Lymphoma: Achievements and Challenges. Acta Haematol. 2019:1-7. 